\title{
Accurate positioning of the 24-hour pH monitoring catheter: Agreement between manometry and pH step-up method in two patient positions
}

\author{
Mehmet Fatih Can, Gokhan Yagci, Sadettin Cetiner, Mustafa Gulsen, Taner Yigit, Erkan Ozturk, Semih Gorgulu, \\ Turgut Tufan
}

Mehmet Fatih Can, Gokhan Yagci, Sadettin Cetiner, Taner Yigit, Erkan Ozturk, Turgut Tufan, Departments of General Surgery, Gulhane Military Medical Academy, Etlik, Ankara, Turkey

Mustafa Gulsen, Semih Gorgulu, Gastoenterology and Hepatology, Gulhane Military Medical Academy, Etlik, Ankara, Turkey

Mehmet Fatih Can, Gokhan Yagci, Sadettin Cetiner, Mustafa Gulsen, Taner Yigit, Erkan Ozturk, Semih Gorgulu, "Reflux Research Group", Gulhane Military Medical Academy, Etlik, Ankara, Turkey

Correspondence to: Mehmet Fatih Can, MD, Departments of General Surgery, Gulhane Military Medical Academy, Kent Koop Mh. 11.Cd. Guneyce Merkez Sit. A/10, 06370, Batikent Ankara, Turkey.mfcan@gata.edu.tr

Telephone: +90-505-4568779 Fax: +90-312-3045100

Received: July 2, $2007 \quad$ Revised: September 14, 2007

\begin{abstract}
AIM: To investigate the agreement between esophageal manometry and $\mathrm{pH}$ step-up method in two different patient positions.
\end{abstract}

METHODS: Eighteen subjects were included in the study. First, the distance from the nose to the proximal border of the lower esophageal sphincter (LES) was measured manometrically. Then a different investigator, who was blinded to the results of the first study, measured the same distance using the $\mathrm{pH}$ step-up method, with the patient in both upright and supine positions. An assessment of agreement between the two techniques was performed.

RESULTS: In the supine position, the measurement of only one subject was outside the range accepted for correct positioning ( $\leqslant 3 \mathrm{~cm}$ distal or proximal to the LES). In the upright position, errors in measurement were recognized in five subjects. Bland-Altman plots revealed good agreement between measurements obtained manometrically and by the $\mathrm{pH}$-step up method with the patient in the supine position.

CONCLUSION: In the case of nonavailability of manometric detection device, the $\mathrm{pH}$ step-up method can facilitate the positioning of the $24 \mathrm{~h} \mathrm{pH}$ monitoring catheter with the patient in the supine position. This should increase the use of $\mathrm{pH}$-metry in clinical practice for subjects with suspected gastroesophageal reflux disease if our results are supported by further studies.

\section{(c) 2007 WJG. All rights reserved.}

Key words: $\mathrm{pH}$ monitoring; Esophageal manometry; $\mathrm{pH}$ step-up method; Gastroesophageal reflux

Can MF, Yagci G, Cetiner S, Gulsen M, Yigit T, Ozturk E, Gorgulu S, Tufan T. Accurate positioning of the 24-hour $\mathrm{pH}$ monitoring catheter: Agreement between manometry and $\mathrm{pH}$ step-up method in two patient positions. World $\mathrm{J}$ Gastroenterol 2007; 13(46): 6197-6202

http://www.wjgnet.com/1007-9327/13/6197.asp

\section{INTRODUCTION}

Although the number of patients with a confirmed diagnosis with gastroesophageal reflux disease (GERD) is low, the condition is thought to affect many more people worldwide ${ }^{[1]}$. The evaluation of patients with reflux symptoms often requires using an advisable diagnostic tool both for distinguishing between physiologic and pathologic reflux, and for the purpose of treatment. New diagnostic tests (multichannel impedance monitoring, wireless $\mathrm{pH}$ monitoring capsules, etc.) have been developed and have become popular over the last decade, especially in leading industrial countries ${ }^{[2]}$. However, the conventional $24 \mathrm{~h}$ ambulatory $\mathrm{pH}$ monitoring continues to be the most common diagnostic test for determining pathologic acid reflux in developing countries. Traditionally, the distal $\mathrm{pH}$ sensor of the monitoring catheter is positioned $5 \mathrm{~cm}$ above the proximal border of the lower esophageal sphincter (LES), since the threshold used to discriminate the diagnostic cut-off level of acid exposure has been validated at this point ${ }^{[3]}$. The most popular method used for detecting this location is prior esophageal manometry. However, several measures have been employed to accurately determine the location of the LES, since manometric measurement (despite being essential to recognize motility disorders) is time consuming, is an invasive procedure ${ }^{[4-10]}$, is uncomfortable for patients, and 
leads to an increase in the cost of the diagnostic work-up.

In the past, the $\mathrm{pH}$ step-up method has been used for this purpose, but the results obtained were conflicting ${ }^{[5,11]}$. It is well known that gravity and body position have an effect on organ position, and in particular abdominal contents $^{[12]}$. In the present study, we investigated the influence of body position on the location of the $\mathrm{pH}$ monitoring catheter during the $\mathrm{pH}$ step-up process. We hypothesized that localizing the $\mathrm{pH}$ probe with the patient in a supine position was more accurate since it is the same position as is used in manometric measurement.

\section{MATERIALS AND METHODS}

\section{Preparation for the study}

The study was conducted between May 2004 and July 2005, in a Military Medical Academic Hospital, in the GI Endoscopy and Manometry Laboratory of the General Surgery Department. Eighteen patients with reflux symptoms, but without hiatus hernia, (ten male and eight female), ranging in age from 22 to 68 (median age 46) years, and referred for esophageal manometry and esophageal $\mathrm{pH}$ monitoring constituted the study group. All esophageal tests were performed by two physicians, each of whom was blind to the results obtained by the other, however, all therapeutic decisions were made by a multidisciplinary gastroesophageal reflux team.

The tests were explained in detail to each patient, and written consent was obtained. All patients had been investigated endoscopically prior to the study, and only two had esophagitis. Patients with esophagitis had grade $\mathrm{B}$ disease according to the Los Angeles Classification ${ }^{[13]}$ and there was no evidence of any serious disease (Barrett's esophagus, carcinoma etc.). Esophageal $\mathrm{pH}$ monitoring determined the presence of GERD in eleven cases (GERD group) while physiologic acid reflux was observed in the remaining subjects (Non-GERD group). All medications which could potentially impact esophageal motility, LES pressure and acid reflux were discontinued fifteen days prior to the tests.

\section{Study protocol}

An eight-lumen polyvinyl catheter with an external diameter of $4.5 \mathrm{~mm}$ [four lumens arranged $90^{\circ}$ from each other for the most distal openings on the same circle, and the remaining four lumens with openings $5,10,15$ and $20 \mathrm{~cm}$ proximal to the distal one respectively (Solar, MMS B.V. Enschede, The Netherlands)] was used for esophageal manometry. Once perfused and filled with distilled water, each lumen was connected to a pressure transducerrecorder system. Perfusion was maintained by fluid flow of $1 \mathrm{~mL} / \mathrm{min}$. After a six hour fast, patients were admitted to the laboratory. Topical anesthesia was applied, and with the patient in the supine position the catheter was introduced through the nose and into the stomach. The distance from the proximal margin of the LES to the nostril, the mean resting pressure and length of the LES, receptive relaxation of the LES, waves of esophageal peristalsis stimulated by wet swallow, and upper esophageal sphincter location were detected by using the stationary pull-through method. Each of the pulling steps was at intervals of $1 \mathrm{~cm}$. The actual location of the proximal margin of the LES was based on the mean location of four radially oriented openings. The catheter was removed after measurements of the upper esophageal sphincter resting pressure and the location site was recorded.

After obtaining the manometric values, a different investigator who was blind to these findings performed the $\mathrm{pH}$ study. For this purpose, we used a double electrode ambulatory $\mathrm{pH}$ monitoring catheter [first sensor on the tip, and another $15 \mathrm{~cm}$ above the first $(\mathrm{pH}$ probe meter, MMS B.V. Enschede, The Netherlands)], calibrated with buffer fluids at $\mathrm{pH} 7.0$ and 1.0, immediately prior to the test. The catheter was introduced into the stomach through the nose, with the patient in the upright position and breathing shallow. After confirmation of acidic $\mathrm{pH}$, the catheter was withdrawn gradually until an abrupt rise in $\mathrm{pH}$ to $>4.0$ ( $\mathrm{pH}$ step-up) was detected. The $\mathrm{pH}$ readings were used to indicate the proximal margin of the LES at the esophagogastric junction. To confirm this point, the catheter was withdrawn at least a further $10 \mathrm{~cm}$ and then re-inserted into the stomach. The process was repeated two more times. The mean value of the three readings was used when there was a difference in the three measurements.

All tests after esophageal manometry were repeated with patients in the supine position. Following this stage, the first investigator rejoined the study and positioned the distal electrode of the catheter $5 \mathrm{~cm}$ above the upper margin of the LES, based on the actual LES location determined by manometric study. A chest x-ray was obtained to ensure against any bends or rolls. If any bend, roll, or dislocation was noted, the catheter location was re-confirmed after making the necessary corrections. Finally, ambulatory $24 \mathrm{~h} \mathrm{pH}$ monitoring was initiated, with comments made on the usage rules of the recording machine.

\section{Statistical analysis}

The results of statistical analysis are noted in the text as mean \pm standard deviation (SD) except for age. To analyze the significance of the results, the SPSS version 11.0 software package program (SPSS Inc, Chicago, IL, USA) was used. All data obtained from manometric measurements were compared between patients with pathologic and physiologic reflux using the MannWhitney- $U$ test. The results of measurement and analysis with respect to esophageal motility above the LES and upper esophageal sphincter functions were not included in this report. An agreement between methods was assessed using the Bland-Altman analysis. This method tests agreement between two measurements, one of which is generally accepted as the gold standard. In addition, correlation between distances measured manometrically and by $\mathrm{pH}$ step-up method was calculated using Spearman's rho test. Results with $P<0.05$ were considered statistically significant.

\section{RESULTS}

Patients referred for esophageal manometry and $24 \mathrm{~h}$ ambulatory $\mathrm{pH}$ monitoring were identified. None of 
Table 1 Comparative results of GERD and non-GERD groups

\begin{tabular}{|c|c|c|}
\hline Variables (mean $\pm \mathrm{SD}$ ) & GERD group & Non-GERD group \\
\hline$n$ (male/female) & $11(6 / 5)$ & $7(4 / 3)$ \\
\hline Age (yr) & $48(26-68)$ & $43(22-61)$ \\
\hline LES length (cm) & $3.27 \pm 0.9$ & $2.86 \pm 0.7$ \\
\hline LES resting pressure, $\mathrm{mmHg}$ & $10.82 \pm 2.6$ & $18.43 \pm 4.0^{\mathrm{a}}$ \\
\hline $\begin{array}{l}\text { Distance: nose to the PB-LES, cm } \\
\text { (by manometry) }\end{array}$ & $42 \pm 3.8$ & $41.7 \pm 3.5$ \\
\hline $\begin{array}{l}\text { Distance: nose to the PB-LES, cm } \\
\text { (by pH step-up in upright position) }\end{array}$ & $44.7 \pm 2.6$ & $43.8 \pm 3.5$ \\
\hline $\begin{array}{l}\text { Distance: nose to the PB-LES, } \mathrm{cm} \\
\text { (by pH step-up in supine position) }\end{array}$ & $43.4 \pm 3.0$ & $42.1 \pm 3.3$ \\
\hline $\begin{array}{l}\text { Clear detection of receptive } \\
\text { relaxation of the LES }(n)\end{array}$ & $9 / 11$ & $7 / 7$ \\
\hline
\end{tabular}

${ }^{\text {a } P}<0.05$ vs GERD group (Mann-Whitney- $U$ test). LES: Lower esophageal sphincter; PB-LES: Proximal border of the LES.

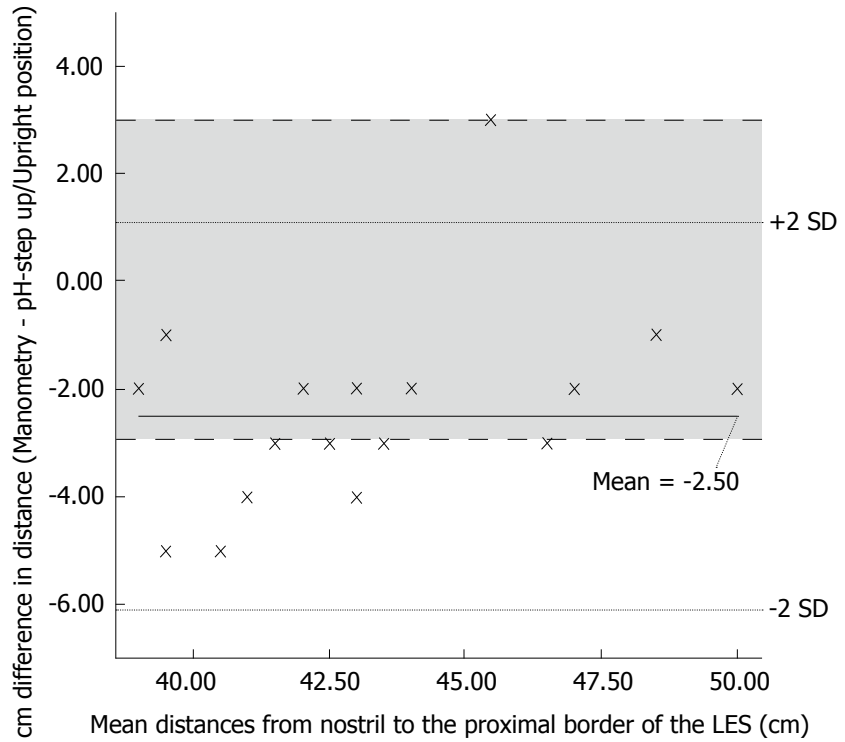

Figure 1 Bland-Altman scatter graph plotted to assess agreement between measurements obtained manometrically and by the $\mathrm{pH}$ step-up method with patients in the upright position. Grey area surrounded by longer dashed line indicates clinically acceptable limits.

the subjects had a hiatus hernia, an esophageal motility disorder, or dysfunction of the upper esophageal sphincter. According to the DeMeester reflux scoring system ${ }^{[14]}$, eleven patients had acid reflux above the pathologic level; while the remaining subjects experienced reflux within the physiologic range (data not provided).

The results of comparison between the LES length and the mean resting pressure of the LES are given in Table 1. The LES length was $3.27 \pm 0.9$ in the GERD group and $2.86 \pm 0.7$ in the non-GERD group $(P=0.268)$. There was a significant difference between the mean resting LES pressures $(10.82 \pm 2.6$ for GERD group and $18.43 \pm 4.0$ for non-GERD group, $P=0.02$ ). In addition, a receptive relaxation at the level of LES was clearly observed in all but two subjects whose mean resting LES pressures were comparatively lower ( 7 and $8 \mathrm{mmHg}$, respectively).

In both study groups, the distance from the nose to the proximal border of the LES, detected manometrically

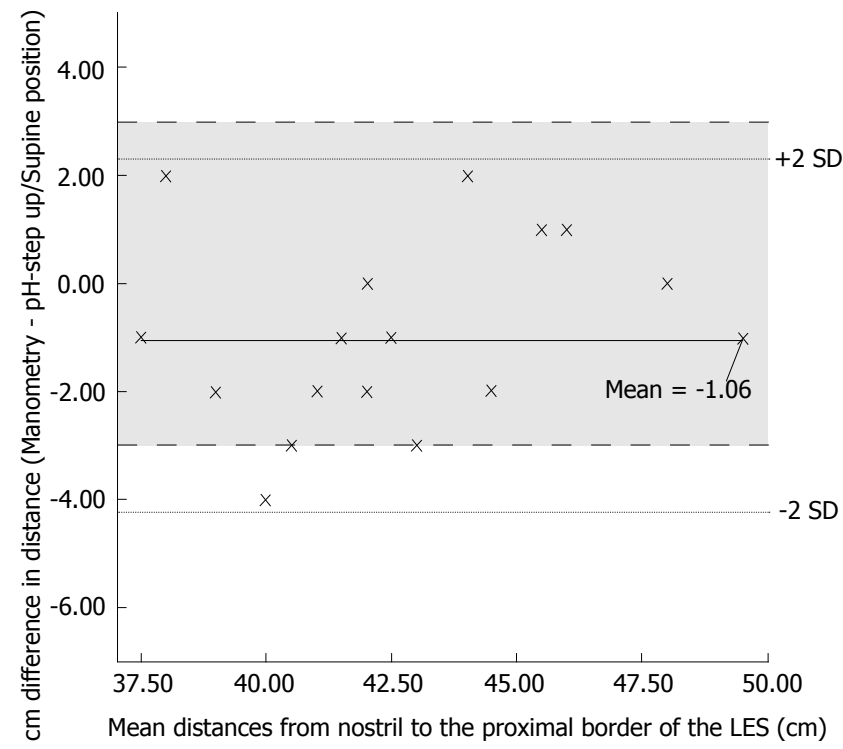

Figure 2 Bland-Altman scatter graph plotted to assess agreement between measurements obtained manometrically and by the $\mathrm{pH}$ step-up method with patients in the supine position. Grey area surrounded by longer dashed line indicates clinically acceptable limits.

was in the range of 37 to 49 (average $41.89 \pm 3.58$ ) $\mathrm{cm}$. The same distance measured by the $\mathrm{pH}$ step-up method ranged between 40 and 51 (average $44.39 \pm 2.95) \mathrm{cm}$ in the upright position, and between 37 and 50 (average 42.94 $\pm 3.09) \mathrm{cm}$ in the supine position. Bland-Altman (bias) statistics showed a good agreement between the distances measured manometrically and by the $\mathrm{pH}$ step-up method. This agreement was found within clinically acceptable limits (difference $\pm 3 \mathrm{~cm}$ ) in measurements obtained with patients in the supine position [difference (mean \pm SD): $-1.06 \pm 1.76$, CI $95 \%$ for supine position and -2.5 \pm 1.82 , CI $95 \%$ for upright position] (Figures 1 and 2). When the differences are analyzed based on the individual results, a difference of $>3 \mathrm{~cm}$ between measurements obtained manometrically and by the $\mathrm{pH}$ step-up method in a supine position was observed in only one subject, where as there were five subjects who had a difference $>3 \mathrm{~cm}$ in the measurements performed in the upright position. A strong correlation was also noted between the two methods (correlation coefficient: 0.842, $P<0.0001$ for manometry/pH step-up in the upright position, and correlation coefficient: $0.891, P<0.0001$ for manometry/ $\mathrm{pH}$ step-up in the supine position, respectively, using the Spearman's rho test). A comparison of the GERD vs nonGERD patients with respect to the measurement obtained with each method-manometry, $\mathrm{pH}$ step-up in an upright position, and $\mathrm{pH}$ step-up in a supine position-showed no statistically significant difference between the two groups.

\section{DISCUSSION}

Our comparative study of LES function in patients with pathologic $v s$ physiologic reflux are in agreement with established data regarding the pathogenesis of GERD. We observed a significant difference in the LES resting pressures of both groups, but not in the LES lengths. 
Similar results were reported in a previous study ${ }^{[15]}$. Another report demonstrated that patients with reflux esophagitis had a lower minimum LES pressure compared with healthy subjects $^{[16]}$. However, we could not determine the receptive relaxation of the LES during wet swallow in two patients with GERD. This was perhaps due to the presence of very low resting pressures, which made measurement of the relaxation pressure difficult. The results of $\mathrm{pH}$ monitoring and the management of patients with pathologic reflux have not been provided in this report.

For an accurate positioning of a $\mathrm{pH}$ electrode, esophageal manometry is widely accepted as the gold standard. Almost all of the other methods recommended for precise $\mathrm{pH}$ electrode placement (endoscopy, fluoroscopy, transnasal fiberoptic laryngoscopy, etc.), require interventions which increase the cost and are more invasive. It is for this reason that we recommend the $\mathrm{pH}$ step-up method, which aims at identifying the proximal border of the LES and only requires the use of $\mathrm{pH}$ monitoring catheter. Our results are based on the detection of an abrupt rise in the $\mathrm{pH}$ as the catheter is withdrawn from the acidic $\mathrm{pH}$ of the stomach into the neutral $(\mathrm{pH}>4)$ environment of the esophagus. In contrast to other studies $^{[5,17,18]}$, some reports have stressed that the $\mathrm{pH}$ step-up method cannot be used for positioning of the $\mathrm{pH}$ electrode in the esophagus ${ }^{[11,19,20]}$. One of these studies by Marples and colleagues ${ }^{[20]}$, suggested that false positioning of the $\mathrm{pH}$ electrode may occur (they detected incorrect positioning of $10 \mathrm{~cm}$ above and $16 \mathrm{~cm}$ below the LES) if the $\mathrm{pH}$ step-up method is used. Pehl and coworkers interpreted this inter-individual variance as a methodological bias, and have explained this on the basis of a lower position of the electrode, presumably because of the inability to detect acidic content secondary to the location of the electrode in the fundic air, when the patient is in the upright position ${ }^{[18]}$. This explanation supports our results, as it suggests that in the supine position, the withdrawal process may help in the correct positioning of the $\mathrm{pH}$ electrode. In fact, it should be recognized that a significant number of physicians interested in GERD and related illnesses have to manage such patients without esophageal manometry, since this test is still not commonly available, especially in community hospitals and small medical centers in developing countries ${ }^{[21]}$. For example, in the city of Ankara (the second largest city in Turkey), there are ten medical departments using esophageal $\mathrm{pH}$ monitoring in adult patients. However, adult participants are investigated by manometry in only five of these centers. This rate is similar to that in pediatric centers; therefore, a correct guide to the use of the $\mathrm{pH}$ step-up method is required.

We proposed to answer the following three questions with this study: (1) Could manometric determination of the LES level be safely replaced by the $\mathrm{pH}$ step-up method? (2) Does the degree of reliability change with the position of patient during pull-through?, and (3) Is there any difference in the measurements of GERD vs non-GERD patients? Esophageal manometry is generally performed when the patient is in a supine position and motionless; this provides the most accurate results from level-oriented pressure sensors. These sensors are properly calibrated prior to each measurement. When an individual reclines from the sitting to the supine position, the fundic air is dispersed throughout the $\operatorname{stomach}^{[2]}$, and thus most of the acidic fluid content of the stomach comes into contact with inferior surface of the LES. Therefore, we hypothesized that the distal electrode of the $\mathrm{pH}$ monitoring catheter more precisely registers the $\mathrm{pH}$ change during the withdrawal process when the patient is in the supine position. Furthermore, as previously reported, LES pressure is higher in the supine position compared to the sitting position, particularly in patients with reflux esophagitis ${ }^{[22]}$. This may facilitate determining the $\mathrm{pH}$ change by preventing the escape of acid fluid into the esophagus, especially in patients whose LES pressure is very low. Despite this, reflux can occur when the patient is in a supine position. Therefore, to avoid a flawed measurement during a possible reflux episode, we repeated the withdrawal process two more times. In another report supporting the reliability of our measurements, the supine position was shown to have no greater influence on the amount of possible acid exposure than that of a 20 degree head-up position in healthy individuals, even if the stomach was full ${ }^{[23]}$. A previous study by Decktor et al showed that the placement of the esophageal $\mathrm{pH}$ monitoring catheter across the gastroesophageal junction did not increase gastroesophageal reflux ${ }^{[24]}$. These findings support our hypothesis with respect to the trustworthiness of the method.

Another possible reason for the difference in the measurements between the upright and supine positions is the effect of gravity on organ placement. It is well known that gravity, plays a significant role in posture and the proprioceptive location of body parts ${ }^{[12]}$. This effect may change an organ's location if it is sufficiently free from adjacent structures. There is a continuous movement of internal organs, caused by factors such as breathing, postural changes, and muscle contractions, which affects the abdominal contents as well as the diaphragm ${ }^{[25,26]}$. Although less than that compared to intra abdominal organs, there is measurable movement with changes in posture of organs within the ribcage. The pericardium, a structure that is adherent to adjacent tissues, has been shown to be mobile in the sagittal plane ${ }^{[27]}$. In light of these observations, it is possible that the LES may have a similar posture-related movement. This would help explain the difference in the measurement between the nostril and the proximal border of LES in the two positions. The present study showed no difference in the distance between nose and the proximal border of the LES between patients with and without GERD. These results were obtained both by the $\mathrm{pH}$ step-up technique as well as by the manometric method (Table 1). This finding is of critical importance as it indicates that the $\mathrm{pH}$ step-up method can be used in both GERD and non-GERD patients.

Measuring the exact location of the proximal border of the LES is presumably impossible because the LES is a ring that is localized in a diagonal plane in association with complex vector volumes ${ }^{[28]}$. Therefore, a difference in distance of up to $2 \mathrm{~cm}$ may be determined by different radially-oriented openings during manometric measurement. For this reason, an electrode positioned 
by any method, at $3 \mathrm{~cm}$ above or below the manometric position, is commonly accepted as accurate ${ }^{[11,18]}$. However, if the electrode is positioned with a difference of $5 \mathrm{~cm}$ or more, a significant error in acid detection can occur. Anggiansah and co-workers reported that in nine out of twenty GERD patients, the clinical diagnoses according to the DeMeester reflux scoring system, was altered if the $\mathrm{pH}$ electrode was placed $10 \mathrm{~cm}$ above the LES $^{[29]}$. Another study showed that there was a two-fold greater measurement of reflux events if an electrode was positioned at $1 \mathrm{~cm}$ compared with $5 \mathrm{~cm}$ above the gastroesophageal junction ${ }^{[30]}$. According to our results, all but one $\mathrm{pH}$ step-up measurement (successful in 17 of 18) made in the supine position was in the acceptable range $( \pm 3 \mathrm{~cm})$, whereas five measurements failed to determine the acceptable pH-step up location (successful in 13 of 18 ) in the upright position. Bland-Altman agreement plots demonstrated the superiority of measurements obtained in the supine position.

These findings clearly indicate the need for accurate placement of the ambulatory $\mathrm{pH}$ monitoring catheter with the patient in a supine position rather than in an upright position. However, the relatively small number of patients that were investigated may restrict the power of this conclusion. The total number of individuals tested was low because the study was designed to include subjects without hiatus hernia. Therefore, additional prospective, doubleblind trials with larger number of subjects are needed for better understanding of this issue. Although patient position during diagnostic work-up may seem to be of little significance, the overall number of individuals who suffer from suspected reflux symptoms makes this issue quite important. In our opinion, physicians who manage patients with GERD should use this technique in clinical practice, especially in centers where manometric devices are not available.

In summary, we consider 24-h pH monitoring as the most valuable diagnostic tool in GERD; until such time as new methods now under development become widely available. Esophageal manometry is still the most reliable method for determining the proximal border of the LES. However, it has several limitations to its routine use. Hence, we recommend an easy method of placement of the ambulatory $\mathrm{pH}$ monitoring catheter. To our knowledge, this is the first study designed to assess the effect of patient's position on $\mathrm{pH}$ monitoring catheter location by an evidence-based clinical trial. Further studies with larger number of subjects are needed to confirm these results. We conclude that if the catheter is positioned when the patient is in a supine position rather than an upright position, the results obtained are more accurate. This may increase both the use of $\mathrm{pH}$ measurements without manometry and improve the diagnosis rate of GERD in developing regions of the world.

\section{ACKNOWLEDGMENTS}

The authors thank Sezgin Ulusahin, Mahsuni Bahar and Nuh Gumus for their support in collecting the data.
COMMENTS

\section{Background}

24-h pH monitoring remains the most crucial test to determine pathologic acid reflux in gastroesophageal reflux disease. Accurate placement of 24-h pH monitoring catheter requires prior esophageal manometry that enables physicians to precisely detect the upper border of the lower esophageal sphincter (LES). Manometric measurement is a relatively invasive procedure, is uncomfortable to patients, and leads to increase in the cost as well as the time spent on investigating each patient. The $\mathrm{pH}$ step-up method has been recommended for this purpose; however, published reports provide conflicting results on its usefulness. In the present study, we investigated the influence of patient posture on the $\mathrm{pH}$ step-up method, which resulted in improvement in the accuracy of the test.

\section{Research frontiers}

In an attempt to find an alternative method to esophageal manometry, different workers have recommended other techniques such as endoscopy, fluoroscopy and transnasal fiberoptic laryngoscopy; however, all of these add new difficulties and additional cost to the diagnostic workup. By contrast, the $\mathrm{pH}$ step-up method only requires the use of a monitoring catheter, however any alteration in the location of the $\mathrm{pH}$ sensor results in false measurement. This fundamental aspect of the study led us to the finding that the location and level of the $\mathrm{pH}$ sensor in the esophagus can alter with posture. To date, this finding has not been reported; and therefore, we decided to prospectively investigate the effect of patient posture on the position of $\mathrm{pH}$ monitoring catheter.

\section{Innovations and breakthroughs}

The present study revealed that the $\mathrm{pH}$ monitoring catheter could be more accurately positioned when the examination is performed with patient in a supine position. Bland-Altman (bias) statistics showed a good agreement between the distances measured manometrically and by the $\mathrm{pH}$ step-up method; however, this agreement was found within clinically acceptable limits (difference $\pm 3 \mathrm{~cm}$ ) only with the measurements obtained with patients in the supine position. The possible factors and effects leading to this result are discussed in the present article.

\section{Applications}

The main debate about the use of the $\mathrm{pH}$ step-up method is focused on the ability to accurately position the monitoring catheter. The results of the present study suggest that examination carried out with the patient in the supine position increases the likelihood of accurate placement. Despite these encouraging findings, because of the small number of patients included in the present study, further trials with larger study population will be required to confirm our findings. If confirmed, this technical step will help make 24 -hour $\mathrm{pH}$ monitoring a routine procedure. We believe that catheter placement for ambulatory $\mathrm{pH}$ monitoring can be more easily managed by using the $\mathrm{pH}$ step-up method.

\section{Terminology}

$\mathrm{pH}$ step-up: defines a sudden increase in the $\mathrm{pH}$ as the $\mathrm{pH}$ monitoring catheter is withdrawn from the acidic content of the stomach into the neutral $(\mathrm{pH}>4)$ environment of the esophagus. It indicates that the $\mathrm{pH}$ sensor has crossed the gastroesophageal junction. Blant-Altman analysis: This test is used to compare the bias (the mean of the differences) and limits of agreement (bias $\pm 2 S D$ of bias) between two methods, one of which is accepted as the gold standard.

\section{Peer review}

In this manuscript, the authors ascertained the accuracy of the step-up method in intra-esophageal pH monitoring. The study was well performed and the conclusion is clear and very interesting.

\section{REFERENCES}

1 Mason RJ, Demeester TR. Physiologic diagnostic studies. In: Zuidema GD, Yeo CJ. Shackelford's Surgery of the Alimentary Tract. 5th ed, Volume I (Esophagus). Philadelphia: WB Saunders Company, 2002: 119-152

2 Hirano I, Richter JE. ACG practice guidelines: esophageal reflux testing. Am J Gastroenterol 2007; 102: 668-685

3 Jamieson JR, Stein HJ, DeMeester TR, Bonavina L, Schwizer W, Hinder RA, Albertucci M. Ambulatory 24-h esophageal 
pH monitoring: normal values, optimal thresholds, specificity, sensitivity, and reproducibility. Am J Gastroenterol 1992; 87: 1102-1111

4 Johnson PE, Koufman JA, Nowak LJ, Belafsky PC, Postma GN. Ambulatory 24-hour double-probe $\mathrm{pH}$ monitoring: the importance of manometry. Laryngoscope 2001; 111: 1970-1975

5 Klauser AG, Schindlbeck NE, Müller-Lissner SA. Esophageal 24-h pH monitoring: is prior manometry necessary for correct positioning of the electrode? Am J Gastroenterol 1990; 85: 1463-1467

6 Singh S, Price JE, Richter JE. The LES locator: accurate placement of an electrode for 24-hour $\mathrm{pH}$ measurement with a combined solid state pressure transducer. Am J Gastroenterol 1992; 87: 967-970

7 DeVault KR, Castell DO. A simplified technique for accurate placement of ambulatory $\mathrm{pH}$ probes. Am J Gastroenterol 1991; 86: 380-381

8 Aksglaede K, Funch-Jensen P, Thommesen P. Which is the better method for location of the gastro-esophageal junction: radiography or manometry? Acta Radiol 2003; 44: 121-126

9 Monés J, Clavé P, Mearin F. Esophageal pH monitoring: are you sure that the electrode is properly placed? Am J Gastroenterol 2001; 96: 975-978

10 Ellett ML, Beckstrand J, Flueckiger J, Perkins SM, Johnson CS. Predicting the insertion distance for placing gastric tubes. Clin Nurs Res 2005; 14: 11-27; discussion 28-31

11 Mattox HE 3rd, Richter JE, Sinclair JW, Price JE, Case LD. Gastroesophageal $\mathrm{pH}$ step-up inaccurately locates proximal border of lower esophageal sphincter. Dig Dis Sci 1992; 37: 1185-1191

12 Morey-Holton ER. The impact of gravity on life. In: Rothschild L, Lister A. Evolution on Planet Earth, The Impact of the Physical Environment. London: Academic Press, 2003: 143-159

13 Malfertheiner P, Hallerbäck B. Clinical manifestations and complications of gastroesophageal reflux disease (GERD). Int J Clin Pract 2005; 59: 346-355

14 Johnson LF, DeMeester TR. Development of the 24-hour intraesophageal $\mathrm{pH}$ monitoring composite scoring system. $J$ Clin Gastroenterol 1986; 8 Suppl 1: 52-58

15 Kraus BB, Wu WC, Castell DO. Comparison of lower esophageal sphincter manometrics and gastroesophageal reflux measured by 24-hour pH recording. Am J Gastroenterol 1990; 85: 692-696

16 Iwakiri K, Hayashi Y, Kotoyori M, Sugiura T, Kawakami A, Sakamoto C. The minimum pressure of the lower esophageal sphincter, determined by the rapid pull-through method, is an index of severe reflux esophagitis. J Gastroenterol 2004; 39: 616-620

17 Anggiansah A, Bright N, McCullagh M, Sumboonnanonda K, Owen WJ. Alternative method of positioning the $\mathrm{pH}$ probe for oesophageal pH monitoring. Gut 1992; 33: 111-114
18 Pehl C, Boccali I, Hennig M, Schepp W. pH probe positioning for 24-hour pH-metry by manometry or pH step-up. Eur J Gastroenterol Hepatol 2004; 16: 375-382

19 Sathya P, Fachnie B, James C, Murphy T, Tougas G. Accuracy of $\mathrm{pH}$ probe placement for 24-hour $\mathrm{pH}$ monitoring: Direct placement of the probe using $\mathrm{pH}$ values vs. manometric placement. Can J Gastroenterol 2003; 17 Suppl A: S139

20 Marples MI, Mughal M, Bancewicz J. Can an oesophageal pH electrode be accurately positioned without manometry? In: Siewert JR, Hölscher AH. Disease of the esophagus. Berlin: Springer-Verlag, 1987: 789-791

21 Wang JH, Luo JY, Dong L, Gong J, Zuo AL. Composite score of reflux symptoms in diagnosis of gastroesophageal reflux disease. World J Gastroenterol 2004; 10: 3332-3335

22 Iwakiri K, Sugiura T, Kotoyori M, Yamada H, Hayashi Y, Nakagawa Y, Kawakami A, Kobayashi M. Effect of body position on lower esophageal sphincter pressure. J Gastroenterol 1999; 34: 305-309

23 Jeske HC, Borovicka J, von Goedecke A, Meyenberger C, Heidegger T, Benzer A. The influence of postural changes on gastroesophageal reflux and barrier pressure in nonfasting individuals. Anesth Analg 2005; 101: 597-600, table of contents

24 Decktor DL, Krawet SH, Rodriguez SL, Robinson M, Castell DO. Dual site ambulatory $\mathrm{pH}$ monitoring: a probe across the lower esophageal sphincter does not induce gastroesophageal reflux. Am J Gastroenterol 1996; 91: 1162-1166

25 Cotter LA, Arendt HE, Jasko JG, Sprando C, Cass SP, Yates BJ. Effects of postural changes and vestibular lesions on diaphragm and rectus abdominis activity in awake cats. J Appl Physiol (1985) 2001; 91: 137-144

26 Delattre JF, Palot JP, Ducasse A, Flament JB, Hureau J. The crura of the diaphragm and diaphragmatic passage. Applications to gastroesophageal reflux, its investigation and treatment. Anat Clin 1985; 7: 271-283

27 Bleetman A, Dyer J. Ultrasound assessment of the vulnerability of the internal organs to stabbing: determining safety standards for stab-resistant body armour. Injury 2000; 31: 609-612

28 Marsh RE, Perdue CL, Awad ZT, Watson P, Selima M, Davis RE, Filipi CJ. Is analysis of lower esophageal sphincter vector volumes of value in diagnosing gastroesophageal reflux disease? World J Gastroenterol 2003; 9: 174-178

29 Anggiansah A, Sumboonnanonda K, Wang J, Linsell J, Hale P, Owen WJ. Significantly reduced acid detection at 10 centimeters compared to 5 centimeters above lower esophageal sphincter in patients with acid reflux. Am J Gastroenterol 1993; 88: $842-846$

30 Lehman G, Rogers D, Cravens E, Flueckiger J. Prolonged $\mathrm{pH}$ probe testing less than $5 \mathrm{~cm}$ above the lower esophageal sphincter (LES): Establishing normal control values. Gastroenterology 1990; 98: A77

S- Editor Zhu LH L- Editor Anand BS E- Editor Wang HF 